\section{The diabetic patient and dental treatment: an update}

L. Wray ${ }^{1}$

VERIFIABLE CPD PAPER
IN BRIEF

- Provides an update on the current management of Type 1 and Type 2 diabetes.

- Outlines the oral health implications of having diabetes.

- Advises on the safe dental treatment of the diabetic patient including under sedation.

- Discusses the possible effects of dental treatment on diabetic control.

This paper has been written to both refresh and update clinicians' knowledge of diabetes. Treatment for patients with diabetes continues to develop with the majority of Type 1 diabetics now using multiple daily injections and an increasing minority using insulin pumps. Blood glucose monitoring and patient education programmes have resulted in more patient involvement in controlling this condition. Type 2 diabetics have had improvement in care provision through the development of shorter acting sulphonylureas and the potential for GLP1 injections. The impact of diabetes on both oral health and quality of life is discussed. Practical suggestions are made regarding the dental treatment of diabetic patients using both local anaesthetic and under sedation. Diabetes continues to be a fickle master for those affected by this condition. The paper is written from the perspective of the 'expert patient'. It is hoped that a greater understanding of this chronic condition will improve both access to, and safety of, dental care for those patients with diabetes.

\section{INTRODUCTION}

As Martin Silink, past-president of the International Diabetes Foundation (20032006), expressed, 'diabetes is understood by few and ignored by many. ${ }^{1}$ With the current global epidemic of this condition it is important that clinicians should have background knowledge of diabetes and its implications for dental care so that barriers to treatment can be avoided.

\section{WHAT IS DIABETES?}

Diabetes is a condition where the body either fails to produce insulin (Type 1 diabetes) or the insulin that is produced is no longer as effective (Type 2 diabetes). A recent study in the United Kingdom reported that diabetes affects $4.3 \%$ of the UK population. ${ }^{2}$ However, using recently introduced WHO criteria, there has been a drastic elevation in the prevalence of diabetes among the older British population (age range 60-79 years): approximately 8\%

Senior Dental Officer, Specialist in Special Care Dentistry, Solent NHS Trust, New Milton Dental Clinic, New Milton Health Centre, Spencer Road, New Milton, Hants, BH25 6EN

Correspondence to: Dr Lucy Wray

Email:morganwray@tiscali.co.uk

\section{Refereed Pape}

Accepted 29 July 2011

DOI: 10.1038/sj.bdj.2011.724

${ }^{\circledR}$ British Dental Journal 2011; 211: 209-215 of British men and 6\% of British women are now known to have diabetes. ${ }^{3}$ of the remainder, approximately $6 \%$ of men and $5 \%$ of women are classified as having undiagnosed diabetes.

Insulin is a hormone produced in the beta cells of the Islets of Langerhans within the pancreas. Insulin is released directly into the bloodstream and is therefore part of the endocrine system. Insulin acts like a key which allows blood glucose to enter the cells around the body for use as an energy supply. Glucose is essential for the body to function properly. The brain is particularly affected by any reduction in blood glucose supply due to its lack of capacity for glucose storage.

There are two main types of diabetes:

\section{Type 1 diabetes}

Type 1 diabetes accounts for approximately $15 \%$ of all diabetics in the UK: it is usually juvenile onset, but can occur at any age. In Type 1 diabetes the beta cells in the pancreas undergo a chronic autoimmune destruction process which results in a long-term lack of endogenous insulin. Scientists and researchers remain unsure as to the exact cause of Type 1 diabetes but it is thought that a viral or other infection may trigger the autoimmune destruction. ${ }^{4}$ The resultant lack of insulin must be replaced via injection, or via an insulin pump. This should be combined with knowledge of dietary carbohydrate (CHO) values such that injected insulin can be adjusted to carbohydrate consumed to avoid large fluctuations in blood glucose levels.

There are many other factors (apart from insulin and $\mathrm{CHO}$ ) which can affect blood glucose levels. These are less easy to control or monitor and include: antiinsulin hormones, eg, adrenaline, growth hormone, cortisol and glycogen; exercise; and anxiety.

The above factors alter from day to day and even hour to hour thus making good blood glucose control a far from simple goal.

\section{Type 2 diabetes}

With Type 2 diabetes there are usually adequate levels (and sometimes even increased levels) of insulin but it is no longer as effective at the cellular level. Using the key analogy, it is as if the key is a bit rusty and it struggles to unlock the cell door to allow the blood glucose to enter. Blood sugar therefore becomes raised but as there is still some effective insulin the levels are not usually as high as with the Type 1 diabetes situation. Hence the undiagnosed Type 2 diabetic may misinterpret or even ignore their symptoms 
of lethargy, increased thirst and drinking, more infections and slower healing. An estimated 20\% of the older British men and women unknowingly have Type 2 diabetes or are at high risk of developing the disease. ${ }^{3}$ There are estimated to be over 500,000 undiagnosed Type 2 diabetics in the UK, ${ }^{5}$ and often diagnosis only occurs following presentation with one of the complications.

\section{TREATMENT}

\section{Type 1}

The Type 1 diabetic must take daily insulin injections to replace the lack of insulin. Previously animal (pork or beef) insulins were used. Synthetic human insulin was developed by the Eli Lilly company in 1980 using recombinant DNA technology. Further refinements to these resulted in the modern 'analogue' insulin. The slight alteration in the synthesised human insulin resulted in two types of analogue insulin.

\section{Bolus or short-acting insulin}

These dissolve more quickly into the bloodstream and are generally injected just before snacks or meals containing $\mathrm{CHO}$. They have a rapid onset of action and their peak action lasts for 2-4 hours.

\section{Basal or long-acting insulin}

These are usually injected once or twice a day. Their onset of action is slow and peak action lasts for 4-12 hours with duration of action being 16 to 35 hours.

The basal insulin deals with the background level of glucose (caused by the anti-insulin hormones) found in the blood during the day. The bolus insulin, given just before eating, deals with the rise in glucose levels after eating. The dosage can be adjusted depending on the value of carbohydrates (CHO) in the meal. The diabetic patient should be conversant with carbohydrate values of different foods. Eating food that has not been prepared at home can sometimes be a best guess process but with experience, carbohydrate assessment becomes more accurate.

Regular blood glucose monitoring means that the levels of insulin can be altered to try to maintain blood glucose levels within the range 4-7 $\mathrm{mmol} / \mathrm{l}$ before meals and $<9 \mathrm{mmol} / \mathrm{l}$ for most of the time.

\section{Type 2}

With Type 2 diabetes treatment is aimed at increasing the effectiveness of the endogenous insulin using metformin and glitazones. Sulphonylureas, which act on the pancreas to help increase insulin production, may also be used. These drugs are supplemented by dietary changes and an increase in exercise to help to prolong the insulin production of the pancreas.

Unlike Type 1 diabetes there is a definite genetic propensity to develop Type 2 diabetes. Fiske reported that people of South Asian or Afro-Caribbean origin have a higher incidence of Type 2 diabetes $^{6}$ and their age of presentation is younger (aged 25) compared to Caucasians (aged 40). Putting on weight is a significant contributing factor to the increase in number of people with diabetes.

With time, all patients with Type 2 diabetes will eventually need to inject insulin: the pancreas will produce less and less effective insulin and the ever increasing blood sugar levels will eventually necessitate insulin injections.

\section{MONITORING THE STATE OF DIABETES}

\section{Blood sugar}

Monitoring is the key to achieving good blood sugar (BS) control. Today, the blood sugar level is recorded using a blood glucose meter. There are many different types of blood glucose meter but the same basic principles of use apply. The machine will use test strips which are inserted into the machine, the coding is checked and a small drop of blood (achieved using a lancet device) is applied to the end of the strip (Fig. 1) Within seconds the blood glucose level in mmol/l will be displayed. The diabetic patient is recommended to maintain a blood sugar of above $4 \mathrm{mmol} / \mathrm{l}$. An automated blood glucose measurement device is on the list of minimum equipment recommended by the Resuscitation Council for medical emergencies in general dental practice 2006. ${ }^{7}$ Training of the dental team in the use of a blood glucose meter is recommended.

The non-diabetic patient will have a blood glucose level of 4-8 mmol/l depending on when they last ate. Unfortunately the average Type 1 diabetic will only spend about $30 \%$ of the 24 hour cycle with blood

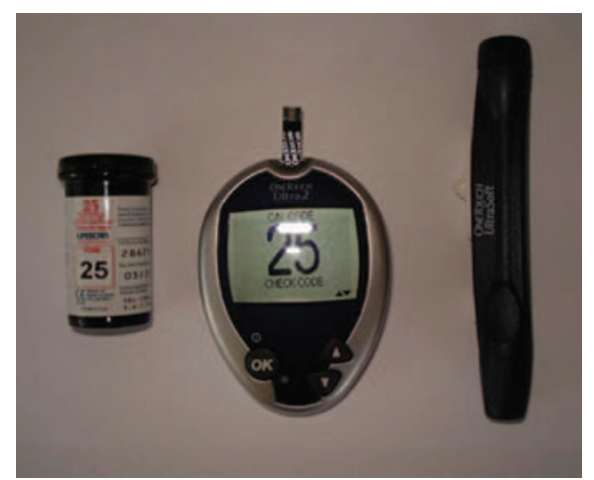

Fig. 1 Blood glucose meter showing coding

glucose levels within this normal range. Fortunately, the body has the capacity to tolerate abnormal blood glucose levels, however, patients may still be aware that they 'don't feel quite right'. Over time the diabetic patient will develop a type of thermostat mechanism such that they can tolerate blood sugars within a certain range but not beyond it. This comfort zone will be different for each diabetic.

If for instance a diabetic is used to their blood sugars running generally higher than recommended (eg 10-20 $\mathrm{mmol} / \mathrm{l}$ ) then they will be far more aware of an oncoming low blood sugar as a blood sugar below $4 \mathrm{mmol} / \mathrm{l}$ will be outside their comfort zone. This however comes at the cost of being at an increased risk of complications. If on the other hand a diabetic is 'tightly controlled' ie their blood sugars are closer to normal (4-7 $\mathrm{mmol} / \mathrm{l})$ then they may have less warning or sensitivity to a fall in blood sugar below $4 \mathrm{mmol} / \mathrm{l}$. This means that they are at an increased risk (approximately 2-3 times) of a severe hypoglycaemia without an effective warning. On the positive side they are at reduced risk of complications. Balancing these concerns of increased risk of complications or increased risk of severe hypoglycaemia is often a source of anxiety to those living with diabetes.

\section{Glycosylated haemoglogin (HbA1c)}

Longer-term diabetes control is carried out by monitoring the level of glycosylated haemoglobin. Haemoglobin is a protein attached to the red blood cells. Its main function is the transportation of oxygen around the body. When the haemoglobin molecule is surrounded by a high glucose level within the bloodstream then some of the glucose will become attached to the haemoglobin. This is called glycosylation. 
This haemoglobin will remain glycosylated until the red blood cell to which it is attached dies (approximately three months). The HbA1c is the ratio of glycosylated haemoglobin to unglycosylated haemoglobin given as a percentage. This level approximates to the average blood sugar level within the last three months. From June 2011 there is to be a change to reporting of patients' HbA1c. The new IFCC HbA1c can be calculated from the old HbA1c (DCCT-HbA1c) and will be expressed in $\mathrm{mmol} / \mathrm{mol}$. For a full explanation and conversion formula readers are referred to the following website: http://www.diabetes.org.uk/Professionals/ Publications-reports-and-resources/Tools/ Changes-to-HbA1c-values/.

The most recent NICE guidance (for Type 2 diabetics) advocates a threshold HbA1c $\geq 6.5 \%$ for the initiation of oral monotherapy and subsequent dual combination therapy after monitoring. An $\mathrm{HbA} 1 \mathrm{c} \geq 7.5 \%$ is recommended as a threshold for further oral therapy escalation or third-line initiation of insulin or exenatide. ${ }^{9}$ If the level exceeds $13 \%$, it is considered as a poorly controlled patient. ${ }^{10}$

In general terms the $\mathrm{HbA1c}$ gives a reflection of the level of blood sugar control the diabetic is achieving. These figures have a bearing on a patient's ability to heal following surgery and the efficiency of their immune system. Patients with an HbA1c above $10 \%$ should be treated with caution.

\section{Ketones}

During periods of hyperglycaemia, it is important for the diabetic to test for ketones (using either blood or urine test strips). Ketones develop when there has been a protracted period of high blood sugar (>16 mmol/l). As the body's cells need for a source of energy continues and a lack of sufficient insulin prevents glucose being used, a situation of 'starvation among plenty' develops. The body is unable to utilise the high levels of glucose so it starts to break down body fats as a source of energy. Ketones are produced as a by-product of this reaction. These ketones have a serious effect on the blood $\mathrm{pH}$ (ketoacidosis) and are toxic.

Diabetic ketoacidosis (DKA) is a hyperglycaemic emergency associated with major morbidity and mortality. However, it is reversible, requiring rapid recognition

\section{Table 1 Three symptomatic levels of hypoglycaemia}

\section{Mild}

Sweating, dizziness, trembling, tingling (hands, feet, lips and tongue), blurred vision, difficulty concentrating/ tiredness and hunger

\section{Moderate}

Odd behaviour, rudeness/spontaneous laughter May appear drunk, bad-tempered, aggressive or confused Uncooperative and refusing to treat low blood sugar

\section{Table 2 Treatment of the three levels of hypoglycaemia}

\begin{tabular}{l|l|l|}
\hline Mild & Moderate & Severe \\
\hline Glucose tablets/sugar & Use liquids/GlucoGel & $\begin{array}{l}1 \mathrm{mg} \text { glucagon injected into } \\
\text { the thigh muscle }\end{array}$ \\
\hline Sweet fizzy drink & $\begin{array}{l}\text { May be less cooperative, } \\
\text { ignore refusal of help }\end{array}$ & \\
\hline $\begin{array}{l}\text { Followed by long acting CHO } \\
\text { (carbohydrates) }\end{array}$ & \\
NB The well-controlled diabetic is 2-3 times more likely to have severe hypoglycaemia
\end{tabular}

and initiation of treatment with fast-acting (soluble) insulin and intravenous fluids. ${ }^{11}$ Mortality rates of 3.9\% were reported in Birmingham, UK, for the period 19711991. ${ }^{12}$ Ketones are excreted in the urine, sweat and breath. They have a distinctive sweet smell often compared to pear drops. A dentist may well be in a prime position to pick up this characteristic smell on the breath. The patient should be advised to contact their diabetes team or GP urgently. Best outcomes for DKA are seen when patients are initially managed in a High Dependency Unit, and this is the practice in the USA. ${ }^{13}$

\section{HYPOGLYCAEMIA}

As mentioned earlier the aim of diabetes treatment is to stabilise blood glucose levels within the normal range. It is of importance for the dental team to know how to manage the situation when blood sugars are outside this range in particular when the blood sugar levels fall ( $<4 \mathrm{mmol} / \mathrm{l})$ and a hypoglycaemia (hypo) develops.

Different diabetic patients will experience different symptoms of a hypoglycaemia (Table 1). These symptoms may alter with time and it is important for the dental team to update the patient's notes with symptoms when they are checking the medical history so they are able to anticipate the cause of any change in behaviour and deal with it appropriately (Table 2).

The majority of the symptoms of hypoglycaemia are caused by the release of adrenaline. It is the adrenaline that causes

\section{Table 3 Causes of hypoglycaemia}

\begin{tabular}{l}
\hline Excess insulin \\
\hline Exercise \\
\hline Delayed/missed meals \\
\hline $\begin{array}{l}\text { Too many oral hypoglycaemics } \\
\text { (in particular the sulphonylureas) }\end{array}$ \\
\hline $\begin{array}{l}\text { Alcohol (causes the blood sugar to } \\
\text { be stored as glycogen in the liver) }\end{array}$ \\
\hline Stress
\end{tabular}

the sweating, shakiness tachycardia and anxiety felt during a hypo. Having a 'hypo' is an unpleasant experience and may cause the patient to exhibit strange behaviour which can be a source of embarrassment on recovery. The fear of having a 'hypo' without pre-warning symptoms can be a great source of anxiety for the diabetic patient; those warning 'signs' being palpitations and sweating. One study has shown that insulin-treated diabetic subjects ranked the fear of hypoglycaemia as highly as that of the chronic complications of nephropathy or retinopathy. ${ }^{14}$ This may be given as a reason for allowing raised blood sugars to persist.

Dr Mark Evans, a leading researcher into hypos, believes that most patients will 'come out' of a hypo given time as the injected insulin wears off and the antiinsulin hormones raise the blood sugar. ${ }^{15}$ Despite this, treatment should be started at the first opportunity to prevent loss of consciousness. For the causes of hypoglycaemia see Table 3. 


\section{Treatment of hypoglycaemia}

Treatment of a 'hypo' is best done at the early stage and can be very satisfying as the response to sugar/glucose is rapid (within 2-4 minutes). If the early signs have not been noticed then it may be more difficult as the patient becomes more irritable and confused (the brain is the first part of the body to be affected). It may be less confrontational to ask the patient if $s /$ he is feeling hungry (a common sign of a hypo) and use GlucoGel (formally hypostop gel) applied to the buccal mucosa. If the early signs are not acted upon the brain function reduces further and consciousness may be lost. Intramuscular glucagon $(1 \mathrm{mg})$ should be injected into the thigh muscle. Recovery should follow within 15 minutes. Recovery following the initial sugar intake should be supplemented with longer lasting carbohydrate eg biscuit, bread or a banana. Following a hypo the diabetic may well have a significant rise in the blood sugar within the next 24 hours due to the effects of the anti-insulin hormones (Somogyi effect).

\section{HYPERGLYCAEMIA}

At the other end of the blood sugar spectrum is hyperglycaemia. Here the blood sugar is raised ( $>10 \mathrm{mmol} / \mathrm{l})$ and there is a situation of 'starvation among plenty' There is plenty of glucose around but the body's cells cannot access it due to the lack of insulin. The following symptoms develop:

- Thirst (this can be extreme)

- Tiredness/lethargy/drowsiness

- Xerostomia

- Excessive urination (with high urine glucose levels)

- Reduced resistance to infection.

Hyperglycaemia tends to develop over a longer period of time and may have several causes:

- Illness/infection

- Not enough insulin

- Stress

- Hormonal (pregnancy/menstruation testosterone and growth hormone)

- Steroids.

The treatment for hyperglycaemia is fast-acting (soluble insulin) for the Type 1 diabetic or an increase in oral hypoglycaemic medication for the Type 2 diabetic. It is important for the hyperglycaemic patient to drink plenty of fluids to prevent

Table 4 Complications of diabetes

Heart: increased arteriosclerosis leading to heart attacks, strokes, and amputation (100/week in the UK)

Nerves: Peripheral neuropathy, autonomic neuropathy

Eyes: Retinopathy, cataracts

Kidneys: Nephropathy

Microvascular

Psychological: Living with a chronic condition. 2-3 $\times$ higher rates of depression

dehydration. The cause of the hyperglycaemia must also be addressed. A dental abscess can cause a serious increase in blood sugar levels with sometimes catastrophic results as reported by Shah et al. ${ }^{16}$

The challenge of improving glycaemic control for the diabetic is driven by two main goals. The first is to reduce the impact of this condition on daily life and the second is to prevent complications the likelihood of which has been shown to increase with poor control. ${ }^{8}$

\section{COMPLICATIONS OF DIABETES}

The complications of diabetes are shown in Table 4, all of which can be subdivided into three categories:

- Macrovascular complications affect the large blood vessels

- Microvascular complications affect the small blood vessels

- The psychological effect is also important to acknowledge.

The Diabetes Control and Complication Trial 1993 recorded the impact of good glycaemic control on the frequency and severity of complications of diabetes. ${ }^{8}$ This randomised controlled trial demonstrated an overwhelming difference in the chance of developing three major diabetic microvascular complications. Good blood sugar control produced a $62 \%$ reduction in relative risk of diabetic retinopathy. There was $56 \%$ less progression of kidney disease and $60 \%$ less progression of nephropathy. The negative effects were a three fold increase in severe hypoglycaemias and also a $1 \mathrm{~kg} /$ year weight gain compared to the nonintensive glycaemic control group.

Seventy-five percent of deaths among the diabetic population are due to heart attacks or strokes. New information from the NHS Information centre (www.ic.nhs.uk) confirms that there are over 300 heart attacks, 300 strokes and over 100 lower limb amputations/ week due to complications from diabetes.

The psychological impact of living with this challenging chronic condition has been underestimated in the past. The more enlightened diabetes teams have appreciated the bi-directional impact of psychological health and diabetes control. A recent report by Diabetes UK highlights the lack of access to psychological support in the UK. ${ }^{17}$ This is despite the fact that clear evidence exists showing that treatment for psychological conditions associated with diabetes (including depression, anxiety and eating disorders) leads to reduced symptoms, improved glycaemic control ${ }^{18,19}$ and a reduction in both psychological distress ${ }^{20,21}$ and healthcare costs. ${ }^{22}$ It is to be hoped that adequate funding will be found such that the recommendations made in the report will be realised and that a more holistic care for the treatment of diabetic patients will result.

\section{DENTAL SCREENING}

In the GDP environment, all new dental patients should be questioned as to their diabetic status. A full periodontal examination should be the recommendation for all known diabetic patients, as part of their routine oral health management. ${ }^{23}$ Patients with diabetes experience periodontal disease more frequently and with greater severity than the general population, ${ }^{24,25}$ there being a bidirectional relationship centred on an enhanced inflammatory response manifested both locally and systemically. ${ }^{26,27}$ Periodontal treatment should be regarded as a possible way of improving glycaemic control. ${ }^{28}$ Current scientific evidence suggests that periodontal treatment could lead to a mean reduction of $0.4 \%$ in HbA1c level. ${ }^{23}$

\section{ADVICE FOR DENTAL TREATMENT FOR THE TYPE 1 DIABETIC PATIENT}

The diabetic patient should be advised to bring four things with them to their dental appointment: 


\begin{tabular}{|c|c|}
\hline Pre-sedation assessment appointment & Rationale \\
\hline 1. Ask the patient how tightly-controlled their diabetes is. & 1. A tightly-controlled diabetic is MORE likely to go hypo. \\
\hline $\begin{array}{l}\text { 2. What are your symptoms of having a hypo and would your } \\
\text { partner/friend notice? }\end{array}$ & $\begin{array}{l}\text { 2. Symptoms vary from patient to patient and alter with time. } \\
\text { These should be updated and recorded. }\end{array}$ \\
\hline $\begin{array}{l}\text { 3. Request that patient brings their own blood glucose meter to all appoint- } \\
\text { ments. Ensure that they are capable of using it. }\end{array}$ & $\begin{array}{l}\text { 3. All diabetics taking insulin should have a blood glucose meter but use may } \\
\text { vary. Most blood glucose meters give a BS result in under ten seconds. }\end{array}$ \\
\hline $\begin{array}{l}\text { 4. Check the escort is aware of the need for food, insulin and testing } \\
\text { at appropriate times and is also aware of hypo symptoms. }\end{array}$ & 4. The escort needs to be aware of the importance of these things. \\
\hline $\begin{array}{l}\text { 5. Warn the patient that they will need to do regular BS testing following } \\
\text { sedation. }\end{array}$ & $\begin{array}{l}\text { 5. Potential alteration in levels of adrenaline, infection and the possible use of } \\
\text { ABs may all alter BS levels so careful monitoring is a sensible precaution. }\end{array}$ \\
\hline $\begin{array}{l}\text { 6. Patient should be advised to bring a snack of both short and long-acting } \\
\mathrm{CHO} \text { with them. }\end{array}$ & 6. Glucose may be available but biscuits/bread/banana may be more difficult. \\
\hline \multicolumn{2}{|l|}{ Sedation appointment } \\
\hline 1. Ask the patient if they have had their insulin and some food. & 1. One without the other may cause problems. \\
\hline $\begin{array}{l}\text { 2. Get the patient to check their BS before sedation. A level between } \\
\text { 7-10 } \mathrm{mmol} / \mathrm{l} \text { would be preferable. }\end{array}$ & $\begin{array}{l}\text { 2. A temporarily raised BS will do no harm and may well help to avoid } \\
\text { a hypo when the patient has a reduced ability to appreciate the symptoms. }\end{array}$ \\
\hline $\begin{array}{l}\text { 3. The sedation team should remain alert to the potential for a hypo to occur } \\
\text { and if in doubt should do a BS test and act appropriately. }\end{array}$ & $\begin{array}{l}\text { 3. Signs of a hypo may be similar to the effects of sedation. This should have } \\
\text { been ascertained at the assessment appointment to avoid mis-diagnosis. }\end{array}$ \\
\hline \multicolumn{2}{|l|}{ Recovery } \\
\hline 1. Check the patient can take their own BS and can interpret the results. & 1. Most diabetics will be able to do this on auto-pilot. \\
\hline $\begin{array}{l}\text { 2. Confirm that the escort is aware of the need for food, insulin and BS testing at } \\
\text { appropriate times for at least the next eight hours. }\end{array}$ & $\begin{array}{l}\text { 2. Only sensible as the escort is assuming responsibility for the patient once they } \\
\text { leave the clinic. }\end{array}$ \\
\hline
\end{tabular}

- Insulin (with pen or syringe) for patient use if required

- Blood glucose meter

- Glucose

- Snack.

The patient should be asked:

- Whether their diabetes is well-controlled (if so they are more likely to go hypo)

- What their signs/symptoms of a hypo are (these should be updated regularly)

- What their HbA1c is.

If on updating the individual signs of a 'hypo' it is found that the patient gets a tingling in their lips, then it would be sensible to do a blood sugar test before administering an ID block. An ID block would otherwise remove any chance of the patient warning the dental team of an oncoming hypo.

A high HbA1c level would put the patient at increased risk of infection and impair their ability to heal following any surgical procedures. While this should not prevent the surgery taking place (particularly if it is thought to be contributing to the poor glycaemic control) it should be carried out with caution in view of the compromised immune system. If the patient has ketones (see above) then any elective surgery should be delayed until the ketosis is resolved using soluble insulin. Communication with the patient's Diabetes Care Team would be advisable.

Cronin et al. ${ }^{29}$ found that diabetes is the only systemic disease with a positive correlation to periodontal disease. The suggestion is that poor diabetic control leads to increased periodontal tissue destruction but the association is cyclical so poor periodontal condition can worsen diabetic control. Hence by improving the diabetes control the periodontal condition may also be positively affected and vice versa.

\section{CONSCIOUS SEDATION FOR THE DENTAL TREATMENT OF DIABETIC PATIENTS}

Currently conscious sedation for dentistry has an excellent safety record. In order to maintain this the following recommendations should be considered for Type 1 diabetics or Type 2 diabetics taking insulin (Table 5).

Sedation clinicians should still use the ASA (American Society of Anaesthesiologists) rating system for assessing the most appropriate setting for sedation. ${ }^{30} \mathrm{~A}$ tightly-controlled insulindependent diabetic (assuming no other co-morbidities) may well be an ASA2 and with due care and attention could be treated in primary care. Secondary care with the potential use of a multi-disciplinary team may be a more appropriate venue for a poorly-controlled diabetic with co-morbidities.

Hopefully, these relatively simple suggestions will help to maintain the excellent safety record of conscious sedation for dentistry. In NO way are they meant to dissuade the clinician from treating the diabetic patient.

\section{POSSIBLE IMPACTS OF DENTAL TREATMENT FOR THE DIABETIC PATIENT}

Some dental treatments may well impact on glycaemic control of the diabetic patient and the clinician should be aware of this and stress the need for careful blood sugar monitoring. For example, if an abscessed tooth is extracted (which as a source of infection has caused a rise in the blood sugar) then a fall in blood sugar may well result and a reduction in insulin requirements may occur. By a similar mechanism antibiotics may also affect the blood sugar and in fact may also cause a further reduction in BS as a consequence of increasing the rate of transit of food in the digestive tract. This in turn reduces the amount of 
carbohydrates being absorbed. Alerting the patient to these possible consequences of treatment and advice to carefully monitor BS may well prevent problems.

Sources of infection in the diabetic patient must be dealt with promptly to avert serious consequences. The clinician should remain alert to the possibility of a patient having undiagnosed diabetes. A GDP who sees a patient on a regular basis will be well positioned to notice certain oral symptoms of hyperglycaemia. This may be xerostomia, a deterioration in periodontal condition which does not respond to treatment, candidal infection, or any smell of ketones on the breath. Such a patient should be questioned as to whether they had been feeling more tired or thirsty lately. Inquiry into any family history of diabetes may also raise the level of suspicion. A referral to the patient's GP for a glucose tolerance test would be wise. The patient may then receive appropriate advice and if necessary treatment preventing or at least delaying the onset of complications.

\section{THE FUTURE}

\section{Type 1}

\section{Insulin pumps}

Currently 3\% of the type 1 diabetics in the UK have an insulin pump (Fig. 2). These machines provide a continuous subcutaneous insulin infusion. Vigilant BS monitoring and $\mathrm{CHO}$ counting is still required. The reservoir in the pump utilises short acting insulin alone. This is released at variable rates during the day which may more accurately accommodate the fluctuating levels of background hormones. The variable basal rates and adjustment of bolus needs at different times of the day allow finer tuning of blood sugar control. This comes at the cost of greater input from the patient. Further progress of currently existing, indwelling glucose sensors may one day close the loop such that the blood glucose readings could influence the rate of insulin delivery thus mimicking the non-diabetic situation.

\section{Islet/pancreas transplants}

Surgery involving the pancreas is notoriously difficult. However, kidney and pancreas transplants are sometimes performed together in diabetic patients with

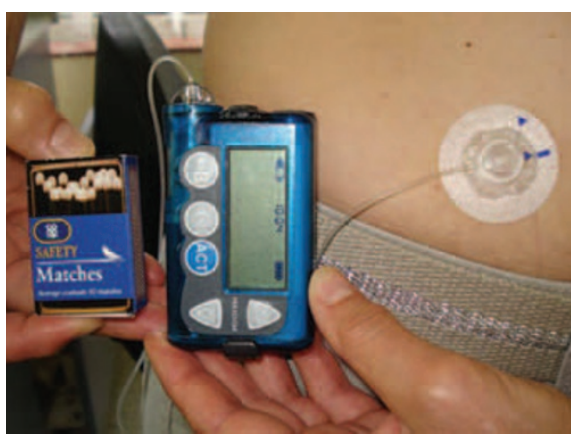

Fig. 2 Insulin pump with infusion set (the box of matches is for size comparison)

kidney failure. Anti-rejection drugs are still required. Islet transplants are in their infancy but have proved successful in those patients who suffer from repeated severe hypoglycaemia.

\section{Stem cells}

Research in this area continues to gather pace with the hope of using the patient's own bone marrow stem cells. Differentiation of these pre-cursor cells into insulin producing beta cells is the aim.

\section{Type 2}

\section{GLP1}

GLP1 is a naturally occurring gut hormone that initiates the pancreas to increase insulin production. GLP1 is usually broken down by the DPP4 enzyme. Research is ongoing into the use of GLP1 injections (either weekly or daily) in combination with DPP4 blocking tablets. This combination may be of benefit to Type 2 diabetics who struggle with the side effects of sulphonylureas such as hypos and weight gain.

\section{CONCLUSION}

With the current rise in numbers of people with diabetes it is important for clinicians to have a background understanding of this condition. The implications it can have for dental care provision should be fully appreciated. The knowledgeable diabetic patient can be a great source of information as to how treatment can best be managed. Encouraging this 'team-work' approach will help to make treatment as problem-free as possible.

However, people with diabetes are not a homogenous group. When diabetes is combined with other conditions eg learning disabilities, autism, dementia or communication difficulties then a multi-disciplinary approach with the diabetes care-team or the GP would help to ensure the optimum treatment for this group of patients.

Many thanks to Dr Graham Manley for sustained encouragement during the production of this paper Thanks also to Dr Shane McCrea (Wootton Lodge, Dental Implant Centre, Bournemouth, Dorset) for proofreading and assistance with citations.

1. Silink M. Turning points in the fight against diabetes. Diabetes Voice 2008; 52: 2.

2. Gonzalez E L, Johansson S, Wallander M A, Rodriguez L A. Trends in the prevalence and incidence of diabetes in the UK: 1996-2005 J Epidemiol Community Health 2009; 63: 332-336.

3. Thomas M C, Walker M K, Emberson J R et al. Prevalence of undiagnosed Type 2 diabetes and impaired fasting glucose in older British men and women. Diabet Med 2005; 22: 789-793.

4. Jasinski J M, Eisenbarth G S. Hypothesis for the pathogenesis of type $1 \mathrm{~A}$ diabetes. Drugs Today (Barc) 2005: 41: 141-149

5. Department of Health. Prevalence of undiagnosed diabetes, by sex and age, adults aged 35 years and over, England. Health Survey for England 2003. London: The Stationery Office, 2004.

6. Fiske J. Diabetes mellitus and oral care. Dent Update 2004; 31: 190-198.

7. Resuscitation Council (UK). Medical Emergencies and Resuscitation - Standards for clinical practice and training for dental practitioners and dental care professionals in general dental practice: a statement from the Resuscitation Council (UK). July 2006. Revised May 2008.

8. The effect of intensive treatment of diabetes on the development and progression of long-term complications in insulin-dependent diabetes mellitus. The Diabetes Control and Complications Trial Research Group. N Eng/J Med 1993; 329: 977-986.

9. National Institute of Clinical Excellence. NICE Clinical Guidance CG66. Diabetes Type 2 (update). London: National Institute of health and Clinical Excellence, 2008. Available from http.//www.nice. org.uk/CG66.

10. Scully C, Epstein J, Wiesenfeld D. The Oxford handbook of dental patient care. 2nd ed. Oxford: Oxford University Press, 2005.

11. Devalia B. Adherence to protocol during the acute management of diabetic ketoacidosis: would specialist involvement lead to better outcomes? Int J Clin Pract 2010; 64: 1580-1582.

12. Basu $A$, Close $C F$, Jenkins $D$, Krentz A J, Nattrass $M$ Wright A D. Persisting mortality in diabetic ketoacidosis. Diabet Med 1993; 10: 282-284.

13. Waller S L, Delaney S, Strachan M W J. Does an integrated care pathway enhance the management of ketoacidosis? Diabet Med 2007; 24: 359-363.

14. Pramming $S$, Thorsteinsson B, Bendtson I, Binder C. Symptomatic hypoglycaemia in 411 type 1 diabetic patients. Diabet Med 1991; 8: 217-222.

15. Evans M. Avoiding hypoglycaemia when treating type 1 diabetes. Diabetes Obes Metab 2005; 7: 488-492.

16. Shah S, Mason C, Brierley J. Underlying problems. Br Dent J 2008; 204: 656.

17. Diabetes UK. Minding the gap - The provision of psychological support and care for people with diabetes in the UK. A report from Diabetes UK. 2008. Available from http://www.diabetes.org.uk/Documents/ Reports/Minding_the_Gap_psychological_report.pdf

18. Lustman P J, Griffith L S, Freedland K E et al. Cognitive behaviour therapy for depression in Type 2 diabetes mellitus: a randomised controlled trial. Ann Intern Med 1998; 129: 613-621.

19. Lustman P J, Clouse R E. Depression in diabetic patients: the relationship between mood and glycaemic control. J Diab Complications 2005; 19: $113-122$.

20. Ismail K, Winkley K, Rabe-Hesketh S. A systematic review and meta-analysis of randomised controlled trials of psychological interventions to improve glycaemic control in patients with type 2 diabetes. Lancet 2004; 363: 1589-1597. 
21. Winkley K, Ismail K, Landau S, Eisler I. Psychological interventions to improve glycaemic control in patients with Type 1 diabetes: a systematic review and meta-analysis of randomised controlled trials. BMJ 2006; 333: 65 .

22. Simon G E, Katon W J, Lin E H B et al. Costeffectiveness of systemic depression treatment among people with diabetes mellitus. Arch Gen Psychiatry 2007; 64: 65-72.

23. Simpson T C, Needleman I, Wild S H, Moles D R, Mills E J. Treatment of periodontal disease for glycaemic control in people with diabetes. Cochrane Database Syst Rev 2010; CD004714.
24. Firlati E. The relationship between clinical periodontal status and insulin-dependent diabetes mellitus. Results after 5 years. J Periodonto/ 1997: 68: $136-140$

25. Sandberg $G E$, Sundberg $H E$, Fjellstrom $C A$, Wikblad K F. Type 2 diabetes and oral health: a comparison between diabetic and non-diabetic subjects. Diabetes Res Clin Pract 2000; 50: 27-34.

26. Van Dyke T E. The etiology and pathogenesis of periodontitis revisited. J App/ Oral Sci 2009; 17(1)

27. Southerland J H, Taylor G W, Moss K, Beck J D, Offenbacher S. Commonality in chronic inflammatory diseases: periodontitis, diabetes and coronary artery disease. Periodontol 2000 2006; 40: 130-143.

28. Sima C, Rhourida K, Van Dyke T E, Gyurko R. Type 1 diabetes predisposes to enhanced gingival leukocyte margination and macromolecule extravasation in vivo. J Periodontol Res 2010; 45: 748-756.

29. Cronin A J, Claffey N, Stassen L F. Who is at risk? Periodontal disease a risk analysis made accessible for the general dental practitioner. Br Dent J 2008; 205: 131.

30. ASA Physical Status Classification System. American Society of Anaesthesiologists 2007. Available from: http://www.asahq.org/clinical/physicalstatus.htm 